\title{
On Processes for Stipulating Temperature Limits at Disposal
}

GUIDO BRACKE, EvA HARTWIG-ThURAT, JÜRGEN LARUE, ARTUR MELESHYN, TORBEN WEYAND

GRS gGmbH, Schwertnergasse 1, 50667 Cologne, Germany, guido.bracke@grs.de

The temperature in a disposal facility for high-level radioactive waste (HLRW) is an issue for long-term and operational safety. In Germany, the Site Selection Act 2017 stipulates a precautionary temperature limit of $100{ }^{\circ} \mathrm{C}$ on the outer surface of the containers of high-level radioactive waste in the disposal facility section. Therefore, this issue is addressed and discussed in a review of the literature [1], contributing to "pending research" which is mentioned in the site selection law.

As temperature limits for disposal concepts are derived based on safety impacts regarding THMCB-processes, this contribution briefly discusses examples of thermohydraulical, mechanical, chemical and biological processes in a disposal facility,. The temperature-dependent processes have been extracted from databases for features, events and processes.

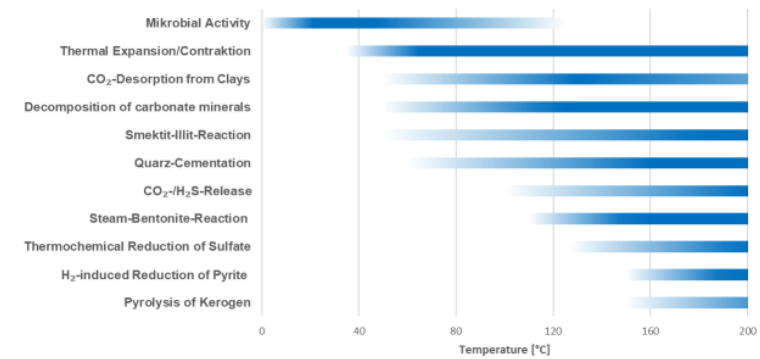

Figure 1: Temperature dependent processes in clay rock

It is concluded that the interactions of all relevant processes in a disposal concept must be considered in order to determine a specific temperature limit for the outer surface of the containers. Therefore, applicable temperature limits may vary for particular disposal concepts and sites in rock salt, clay stone and crystalline rock. Known temperature limits range from approx. 80 to $230{ }^{\circ} \mathrm{C}$, which appear to be feasible from a safety point of view.

Furthermore, the feasibility of retrieving and recovering HLRW is discussed for this temperature range. Technical solutions for retrieval and design options for recovery seem to be viable up to temperatures of $200{ }^{\circ} \mathrm{C}$ with different, sometimes severe, downsides according to expert judgement.

[1] Bracke, G.; Hartwig-Thurat, E.; Larue, J.; Meleshyn, A.; Weyand, T. (2019): GRS-A-3948 / BfE-RESFOR-003/19. https://doris.bfs.de/jspui/handle/urn:nbn:de:0221-

2019111520402 (accessed on 4 January 2020) 